\title{
INDEX OPUSCULORUM
}

\section{QUAE VOLUMEN PRIMUM COMPLECTITUR.}

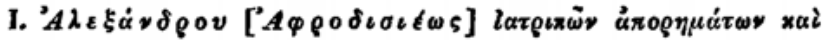

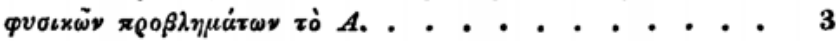
- - - - - - - ๙ò B. . . . . . . . . . . . 52

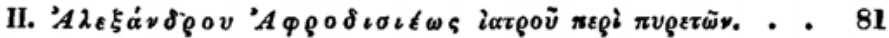

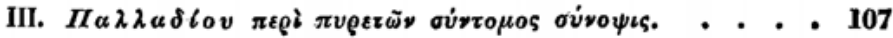

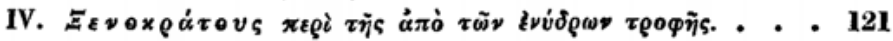

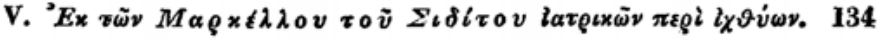

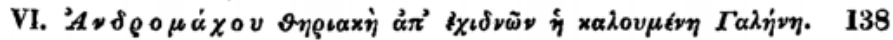

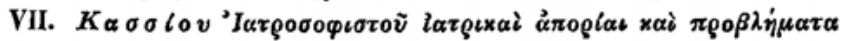

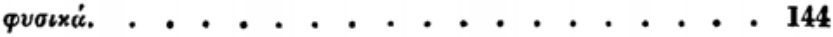

VIII. $\Theta \varepsilon \circ \varphi v \lambda \dot{a} \times \tau$ เ

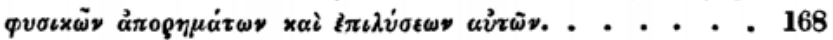

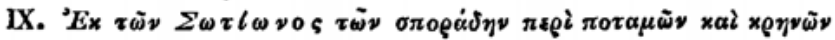

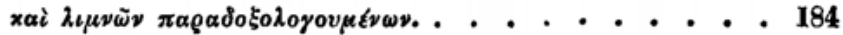

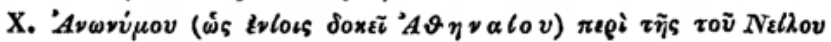

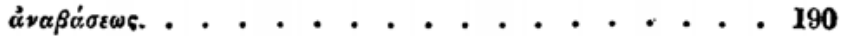

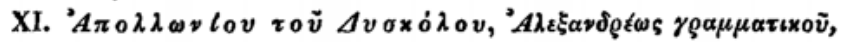

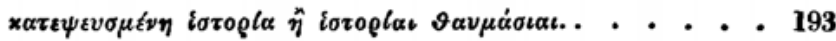

XII. 'A $\sigma \times \lambda \eta \pi \iota \alpha \delta \tilde{\omega} \nu$ vं

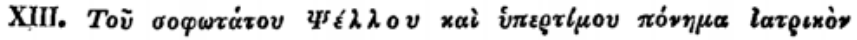

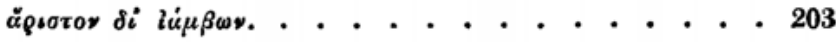

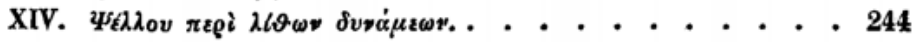

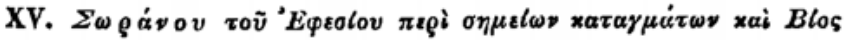

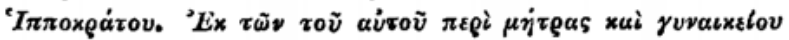
aldolov. . . . . . . . . . . . . . . . . . 248

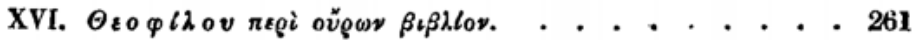

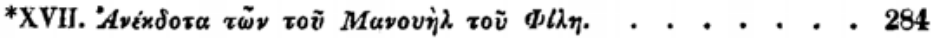

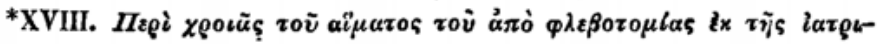

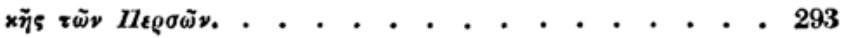

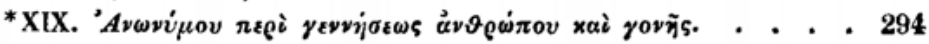

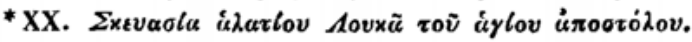

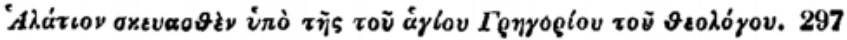




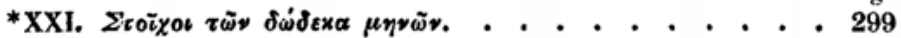

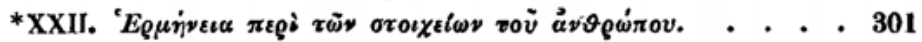

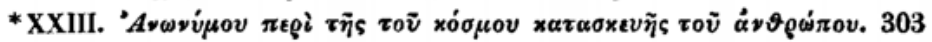

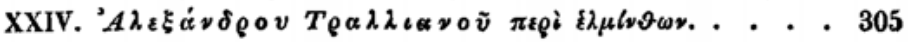

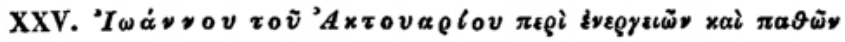

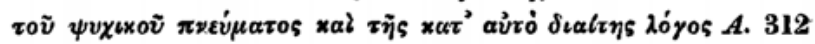
- - - - - - - - - - - גó - - - 350

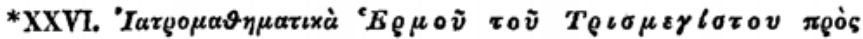

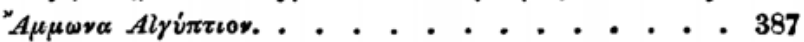

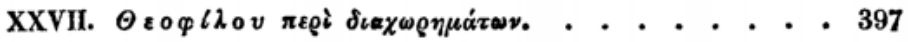

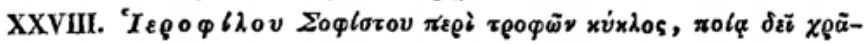

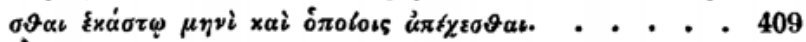

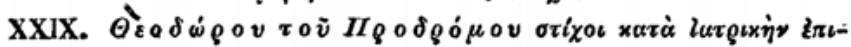

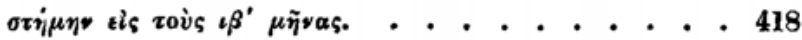

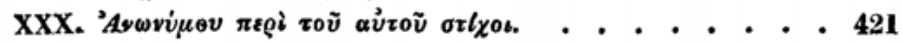

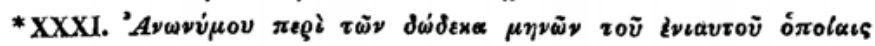

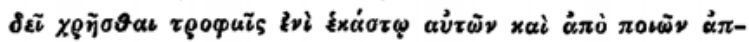
, $\{\chi \varepsilon \vartheta$

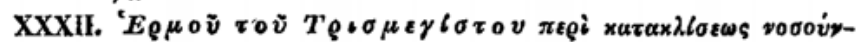

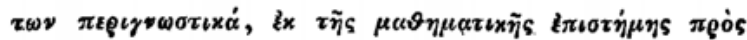

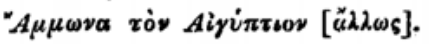

\section{O R R I G E N A.}

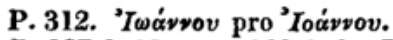

P. 3871.11 et p. 388 1. 6. Pro $\tau \ddot{\varphi} \sigma \chi \dot{\eta} \mu \alpha \tau_{b}$ lege $\tau \tilde{\varphi} \sigma^{\top}$.

Quin alia nonnulla me fugerint $\sigma \varphi \dot{\alpha} \lambda \mu \alpha \tau \alpha$ plagulas corrigentem vix dubito. Precor, ut benevolus lector in memornam sibi revocet, quid accidere soleat iis, qui Libyae peragrant deserta. Oculis enim vix

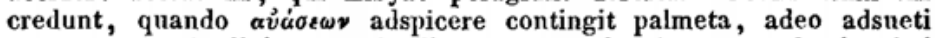
arenarum vastitudini, ut animalium spectra hominumque, lassi animi deliramenta, in ipso' coelo conspexisse sibi videantur. 